topics were complimented with small-group sessions in which case studies were discussed and diagnoses made. It was agreed that this basic approach to animal health should be developed in the region, to equip veterinarians better for the pivotal role they must play in ecosystem health.

In the technical session, case studies were presented for the application of quad-copters and fixed wing drones for vegetation monitoring, counts of shorebirds and turtles, and monitoring of herd dynamics of Arabian oryx Oryx leucoryx. Delegates discussed the opportunities, constraints, and challenges relating to the expansion of drone-based ecological monitoring in the Arabian Peninsula.

PHILIP SEDDON Department of Zoology, University of Otago, Dunedin, New Zealand. E-mail philip.seddon@otago.ac.nz

MIKE KNIGHT South African National Parks, \& Centre for African Conservation Ecology, Nelson Mandela University, Port Elizabeth, South Africa

Gerhard SteEnKAmp Department of Companion Animal Clinical Studies, Faculty of Veterinary Science, University of Pretoria, Onderstepoort, South Africa

Craig Hilton-Taylor IUCN Red List Unit, Cambridge, UK

DAVID MALLON Manchester Metropolitan University, UK, \& IUCN Species Survival Commission

HELEN SENN Royal Zoological Society of Scotland, Edinburgh Zoo, Scotland, UK

\section{First observations of the impacts of Hurricane Maria on the endemic imperial amazon}

On 18 September 2017 the Caribbean island of Dominica was struck by the category five Hurricane Maria. This is the strongest storm on record for the island, considerably more powerful than the previous most destructive, Hurricane David in 1979. Although damage assessments from Maria have yet to be completed, environmental impacts are expected to be severe. Hurricane David, which caused widespread destruction only in the island's south, destroyed or damaged at least 5 million trees (Bird Conservation International, 1, 11-32). Maria encompassed the whole of Dominica and is thus expected to have caused more severe damage. Early estimates from the Forestry and Agriculture Department suggest at least $30 \%$ of trees were felled nationally, with much of the remaining $70 \%$ being stripped of foliage and fruits.

This damage is expected to have severe consequences for Dominica's biodiversity, including its national bird, the endemic and Endangered imperial amazon Amazona imperialis. Pre-Maria estimates suggested a population of $250-350$ individuals across three disjunct localities; Morne Diablotin, the Northern and Central Forest Reserves, and Morne Trois Pitons National Park (http://www.iucnredlist. org/details/22686411/o). Given that Hurricane David reduced the species' population to just 40-60 birds (Bird Conservation International, 1, 11-32), the impacts of Maria are of great concern. The first observations of Maria's impacts on A. imperialis are presented here, based on records compiled by the Forestry and Agriculture Department since 18 September 2017, and a field visit by CAP during 16-23 January 2018.

By 23 January 11 confirmed sightings of $A$. imperialis had been collated from nine locations across the island, all of which are outside the pre-Maria range for the species. At two locations individuals were seen foraging on fallen grapefruit and guava in populated areas. In the latter case a single bird was observed eating guava daily for 2 months post-Maria but subsequently visits became less frequent.

These sightings indicate two things. Firstly, that the species still persists at several locations. Secondly, that Maria has pushed the species out of its natural habitat of high altitude forests, with all reported localities being low-lying sites near human settlements (areas where A. imperialis does not normally occur). The species may have been forced into these areas by the destruction and defoliation of highland trees and consequent reduction in food resources. As a result, there may now be increased foraging pressures through competition with the endemic Amazona arausiaca at these lower elevations.

As in the aftermath of Hurricane David, several weak, grounded A. imperialis individuals were found postMaria. Two presumed male birds, both underweight and dehydrated, were brought to the Parrot Conservation and Research Centre. One died shortly after arrival; the second, which was found in Salisbury town on 18 December, was held at the Centre alongside an 18-year-old female who had been there from a young age. On 18 March 2018 both birds were moved to a facility in Germany. Only a few individuals are held elsewhere, including one at the Rare Species Conservatory Foundation, Florida, which was previously bred at the Parrot Conservation and Research Centre.

These observations indicate the conservation status of $A$. imperialis is of great concern, given the detrimental impacts of previous hurricanes on the species. Climate change scenarios predict that high intensity Caribbean hurricanes such as Maria will become more frequent (Nature Geoscience, 3, 157-163). A similar event in Dominica in the next few years, with no interceding recovery period, could have disastrous consequences for the species. During 2018 we plan to make a formal assessment of post-Maria A. imperialis populations, the results of which may warrant a re-examination of the species Red List status. 
Charlotte A. Palmer and Thomas E. Martin Operation Wallacea, Old Bolingbroke, Lincolnshire, UK.

E-mail charlotte.palmer@opwall.com

STEPHEN DURAND Division of Forestry Wildlife and National Parks, Ministry of Agriculture and Fisheries, Roseau, Commonwealth of Dominica

Myles Lamont TerraFauna Wildlife Consulting Inc., Surrey, British Columbia, Canada

\section{Successful prosecution of slow loris traders in Indonesia}

On 15 February 2018 a wildlife trader in Lubuk Basung, West Sumatra, Indonesia, was sentenced to 3.5 years in prison, with a fine of IDR 100 million (c. USD 7,250) and a 6-month subsidiary sentence, after his arrest last year for trading slow lorises (Nycticebus spp.). A trafficker was sentenced to 3 years in prison with the same fine and subsidiary sentence. The perpetrators were tracked by posts on their Facebook pages that advertised the animals for sale.

Indonesia is home to seven species of slow loris, and all of them are categorized as threatened (with two Critically Endangered) on the IUCN Red List, and all are included on Appendix 1 of CITES. Slow lorises were included on Indonesia's list of protected species in 1973, and buying, selling or keeping them as pets is illegal. According to Indonesia's Law No. 5 (1990) on the Conservation of Biological Resources and Ecosystems, perpetrators can receive a maximum of 5 years in prison and a maximum fine of IDR 100 million. Despite the extreme threat of illegal trade to the survival of slow lorises in Indonesia, open trade in markets or on social media still flourishes.

The convicted trader offered slow lorises and other wildlife, including the protected changeable hawk-eagle Nisaetus cirrhatus, for sale on his Facebook page. The asking price for a Sumatran slow loris Nycticebus hilleri offered for sale on 30 August 2017 was USD 36. On 23 September 2017 the local authorities arrested the wildlife trader whilst he was in possession of six Sumatran slow lorises and two albino common palm civets Paradoxurus hermaphroditus, the latter for sale at USD 109 each, and on the same day a wildlife trafficker with three Sumatran slow lorises was arrested. The nine slow lorises comprised two babies, two juveniles and five adults (seven females, two males). They must have been obtained recently from the wild as they were still healthy and none had their teeth cut (slow lorises are the only venomous primate and traders often cut their teeth to make them more suitable as pets).

Two weeks later, eight of the nine Sumatran slow lorises were released in the Bung Hatta Forest Park, east of the city of Padang. Two slow loris species occur on the island of
Sumatra, yet their distribution has not been documented, nor has any study been made of their behavioural ecology. These are crucial prerequisites for release. No data are available regarding whether assessment of the quality and suitability of the habitat were made prior to release. Reintroductions of non-endemic species, as well as introducing animals into areas with no suitable habitat, are additional threats to slow lorises throughout Asia.

Prosecuting and sentencing law breakers punishes the offenders and acts as a deterrent for future law breakers. This case is one of few in which a wildlife trader and wildlife trafficker have been successfully prosecuted and sentenced for trading and trafficking slow lorises in Indonesia. We hope that these convictions represent a changing trend in wildlife enforcement in the country.

K.A.I. NEKARIS and V. NIJMAN Nocturnal Primate Research Group and Oxford Wildlife Trade Research Group, Oxford Brookes University, UK. E-mail anekaris@brookes.ac.uk

\section{Sightings of reintroduced northern bald ibis Geronticus eremita crossing between Spain and Morocco are probably hand-reared rather than wild-born}

The report of six northern bald ibis Geronticus eremita arriving in Morocco from Spain in November 2016 (Muñoz \& Ramirez, Oryx, 51, 204-205) was claimed to be the first confirmed sighting of the reintroduced Spanish population crossing from Europe to Africa. Significantly, there have been several additional sightings of birds leaving from Spain and crossing to Africa before and since this date (Migres Foundation, 2016 \& 2017, Unpublished Reports). We present these data and cross-reference them to timings and information from the reintroduction project Proyecto Eremita (López \& Quevedo, 2016, pp. 5457, in Boehm \& Bowden, eds, Northern Bald Ibis Conservation \& Reintroduction Workshop) in Andalusia, Spain.

Post-breeding observations of soaring birds since 1999, by the Migres Foundation observation teams at Tarifa, Cazalla and Algarrobo in southern Spain during July-December, have recorded northern bald ibises on at least 15 occasions (Table 1). These have mainly been birds leaving Spain towards Morocco. The highest numbers were observed in 2016, and these include the six birds confirmed to arrive in Tangiers by Muñoz \& Ramirez. Table 1 shows crossings both before and after, as well as a group in July 2016 that appears to have made the crossing and then returned, minus one individual, to Spain the following day.

The observation of 11 birds that crossed on 23 September 2016 is of interest because 11 hand-reared juveniles, released as part of a larger group of 25 in July, disappeared from 